I hope that Mr. Mortimer's final sentence will not prove to be a true forecast and that all officers will realize that radar will not prevent collisions, that when the close-quarter situation is reached they will have already had the best opportunities for using its information, and that their greatest chance of safety then lies in extreme circumspection.

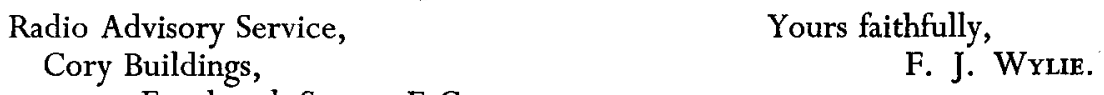

I 7 Fenchurch Street, E.C.3.

SIR,

\title{
ASTRO-FIX BY RANGES
}

I was very interested to read Professor Collins's paper on astro-fixing by ranges (Vol. IV, p. 20); and also the letters from Dr. Palm and Rektor Möhn in the following number.

Restricting the difference in azimuth to $12^{\circ}$ in Schöenberg's method may reduce errors due to accelerations and simplify the observing, but it also reduces the pairs of bright stars that can be used; so much so that either the method could seldom be used or present-day sextants would need much more 'transparent' optical systems for the fainter stars.

Although precomputed tables are desirable, they would be voluminous, and perhaps computation from Schöenberg's formula would suffice: the formula looks simple in that the computation should be short.

If the sight is to be reduced by plotting on a gnomonic chart, as Professor Möhn suggests, the average scale should be not less than $I: 4 \mathrm{M}$; the area of the charts required would then be at least 40 square feet. This covers an octant of the globe. All the sheets would have to be carried for every flight and several used for plotting each observation, some twice. Lines to be drawn on the charts would be up to 8 feet long. Thus reduction by plotting would demand more drawing accuracy and space than is available in the air.

An alternative graphical method, somewhat laborious, would be to prepare before the flight a set of gnomonic charts covering the area of sky to be traversed, drawing in the great circles for all the visible pairs of stars against coordinates of S.H.A. and declination. Plotting the D.R. position on the gnomonic chart would show instantly which stars were suitable for observation and, on making the observation, the position line could easily be transferred to the plotting chart.

But without a simple observing instrument and some means of 'preselection' of suitable stars, astro-navigation by ranges will not be able to compete for popularity with the standard method of aerial astro-navigation with sextant and H.O. 249 (where, incidentally, the stars need not even be identified).

White House,

Hemp Lane,

Yours faithfully,

Wigginton.

J. D. Proctor. 